\title{
EFFECTS OF PARTICULATE MATTER EMISSIONS OF DIESEL ENGINE USING DIESEL-METHANOL BLENDS
}

\author{
A.F. Yusop $^{1 *}$, R. Mamat ${ }^{1,2}$, M.H. Mat Yasin $^{1,2}$ and Obeed M. Ali ${ }^{1}$ \\ ${ }^{\mathbf{1}}$ Faculty of Mechanical Engineering, University Malaysia Pahang \\ 26600 Pekan, Pahang, Malaysia \\ Phone: +609-424-2246 ; Fax : +609-424-2202 \\ *Email: fitri43@gmail.com \\ ${ }^{2}$ Automotive Engineering Centre, Universiti Malaysia Pahang, \\ 26600 Pekan, Pahang, Malaysia.
}

\begin{abstract}
In this work, palm methyl ester (PME) was added to methanol-biodiesel fuel in order to reduce the emissions. For diesel engines, alcohols are receiving increasing attention because they are oxygenated and renewable fuels. Therefore, in this study, the effect of the PM emission level of a four-cylinder, naturally aspirated, indirect injection diesel engine has been experimentally investigated by using methanol-blended diesel fuel from $0 \%$ to $20 \%$ with an increment of $5 \%$. The effects of methanol on particulate matter (Laurens, Koolwijk, \& De Maat) components, soluble organic fraction (SOF) and dry soot (DS) using different types of fuel blend were investigated. Using a composite filter, the ester-methanol-diesel characteristics such as mass concentration in terms of PM, SOF and DS were analyzed under different engine operating conditions. The results show that the combination of $10 \%$ of methanol with $20 \%$ of palm methyl ester produces lower PM emissions. It is shown that PME20M10 of methanol-biodiesel fuel can reduce the PM emissions effectively for all load conditions.
\end{abstract}

Keywords: Particulate matter; diesel engine; soluble organic fraction; dry soot; PME; methanol.

\section{INTRODUCTION}

Research on improving fuel economy and reducing exhaust emissions has become a major activity in engine combustion and development due to concerns about the fuel shortage and environmental protection (Atadashi, Aroua, \& Aziz, 2010; Azad, Ameer Uddin, \& Alam, 2012; Aziz Hairuddin, Wandel, \& Yusaf, 2013; Mamat, Yusop, Rahim, Aziz, \& Shah, 2013; Sundar Raj \& Sendilvelan, 2010). On the other hand, due to limited crude oil resources, the research and development of alternative fuel engines has been receiving serious attention (Kulakoğlu, 2009; Yusaf, Hamawand, Baker, \& Najafi, 2013). Usually, alternative fuels produce cleaner emissions compared to mineral diesel in the combustion processes. Introducing these alternative fuels will be beneficial to slow down global petroleum consumption and improve emission levels (Ghobadian, Najafi, \& Nayebi, 2013; Rahim, Mamat, Taib, \& Abdullah, 2012; Wang, Song, Zou, Liu, \& Zhou, 2008). Methanol has received increasing attention because it can be blended with conventional fuels or be used as an additive in biodiesel production (Mat Yasin, Yusaf, Mamat, \& Fitri Yusop). Besides, methanol also has a high octane number and oxygen content. Thus, methanol can give better results in terms of combustion characteristics in spark ignition engines (Mat Yasin, Mamat, Sharma, \& Yusop, 2012; 
Sayin, Uslu, \& Canakci, 2008). However, some difficulties have been reported when using methanol in diesel engines due to the low cetane number, high latent heat of vaporization and long ignition delay (Saeed \& Henein, 1989). In order to overcome these problems, several methods have been introduced by researchers, such as dual injection, methanol-diesel fuel blends and methanol-diesel fuel emulsion (Kulakoğlu, 2009).

In terms of emission levels, diesel engines fueled with mineral diesel have caused environmental pollution. Thus, to bring down the emission level, the European Commission has published an emissions directive (2005/55/EC for Euro 4/5, etc.) (Ozsezen, Canakci, \& Sayin, 2008). In order to make this successful, many researchers have started to use methanol blends with diesel fuel to lessen the air pollution and also as an alternative fuel to replace mineral diesel. Previous research by Huang et al. (2004) shows that increased methanol content in the diesel-methanol mixture reduces smoke, $\mathrm{CO}$ and THC emissions but on the other hand increases $\mathrm{NO}_{\mathrm{x}}$ emissions. However, during combustion, gaseous and particulate matter exhausted from the diesel engine results in air pollution. Besides, some parameters such as fuel composition, oil lubrication and engine operation can affect the particle formation and concentration (Abdul-Khalek I.S. \& J.H., 1996). Thus, it can cause a hazard to human health. Diesel Particulate Matter (DPM) also consists of a soluble organic fraction (SOF) and dry soot (DS), including sulfate. Previous research shows that diesel particles have been a great concern due to their adverse effects in urban areas (Lighty, 2000). Many toxicological and epidemiological studies have reported on the adverse health effects of particulate matter (PM10, PM2.5) (H, 2005). There is much evidence of health effects associated with ultra-fine particles with a diameter below $100 \mathrm{~nm}$ (Brown, 2001) and some of these can penetrate the cell membranes, enter the blood and even reach the brain (Oberdörster, 2004). Thus, the reduction of the particulate matter (Laurens et al.) concentration in diesel exhaust gas is becoming a crucial issue in industrial societies and among academic researchers (Bhaskar, Nagarajan, \& Sampath, 2010; Chen, Shi-Jin, \& Jian-Xin, 2007; Gangwar, Gupta, \& Agarwal, 2012; Mohanamurugan \& Sendilvelan, 2011). On the other hand, it is also important to investigate the PM concentration of biodiesel and other alternative fuels, since PM from these fuels is likely to have a different chemical composition (Chen et al., 2007; Qi, Chen, Matthews, \& Bian, 2010). Many researchers have reported that the main factor affecting PM emission is the fuel oxygen content. The results obtained by Miyamoto, Ogawa, Nurun, Obata \& Arima (1998) show that when the oxygen content is approximately $30 \%$ mass in diesel fuel, the smoke levels approach zero. However, some researchers concluded that the differences depend on the chemical structure or volatility of a given oxygenate (Liotta \& Montalvo, 1993). The numerical modeling of the chemical kinetics has been investigated in the primary soot formation region (Kitamura, Ito, Senda, \& Fujimoto, 2001). Therefore, these studies provide information on the behavior of PM reduction using oxygenated diesel blends.

In this study, in order to prevent the separation of methanol from diesel, the ester was added to the methanol-diesel blend fuel to act as a co-solvent. The methanol percentage in the blended fuels used in this experiment was up to $20 \%$ by volume. Furthermore, the cetane number and viscosity for ester is higher than diesel and methanol, so it could balance the ester-diesel-methanol blended fuel in order to meet the requirements of a diesel engine. In order to understand the effects of methanol in a diesel engine, more attention was paid to the PM component, SOF and DS. Based on the above considerations, the objective of this study is to clarify the effects of the 
particulate matter (Laurens et al.) of an IDI diesel engine using diesel-methanolblended fuel in terms of soluble organic fraction (SOF) and dry soot (DS).

\section{RESEARCH METHODOLOGY}

Engine tests were carried out on a bench-mounted and instrumented automotive diesel engine. A four-stroke multi-cylinder Mitsubishi 4D68 SOHC 2.0 liter was used in this study. Table 1 shows the details of the engine specifications and Table 2 shows the fuel properties. A Kistler 6041A water-cooled piezoelectric pressure transducer was flush mounted with the cylinder head to measure the combustion pressure. The flush mounting was selected in order to minimize the lag in the pressure signal and to avoid pipe connecting passage resonance. The test bench was equipped with Cole Palmer pressure gauges and K-type thermocouples for mean temperatures and pressure measurements in order to characterize and monitor accurately the engine's operating mode. A Kane gas analyzer complete with a 3 meter sampling probe was used for emissions measurements. The sampling probes of the smoke meter and gas analyzer were mounted centrally at the end of the engine exhaust pipe. The Kane gas analyzer was used to measure and monitor the exhaust emissions of the engine, including NOx, carbon monoxide $(\mathrm{CO})$, carbon dioxide $\left(\mathrm{CO}_{2}\right)$ and unburned hydrocarbon. The engine was mounted with a Kistler CAM crank angle encoder type 2613B connected to a Kistler signal conditioner type 2613B2 for crank angle measurement and combustion characteristics. The crank angle encoder was connected to a PC DEW-800 with connecting cable type 2613B3 using the signal conditioner. A $150 \mathrm{~kW}$ eddy-current brake ECB dynamometer equipped with a Dynalec load controller was directly coupled by a shaft. The engine and dynamometer were mounted on a seismic steel bed $(2.49 \mathrm{~m} \mathrm{x}$ $1.3 \mathrm{~m}$ ) to absorb the engine vibration emitted during the trial. Air flow and fuel flow rates were measured by a Centertek anemometer and AIC fuel flow meter respectively. Figure 1 shows the diesel engine specifications with four cylinders. A composite filter was used to capture the PM in the exhaust tail pipe. This was used to filter waste combustion flue gas and particulate matter, and was placed in a gas line connected sampler using heat-resistant plastic pipes. The type of filter used was a composite with a diameter of $0.6 \mathrm{~mm}$. Table 3 shows the filter specifications.

Table 1. Specifications of Mitsubishi 4D68 diesel engine.

\begin{tabular}{lc}
\hline \multicolumn{1}{c}{ Description } & Specification \\
\hline Number of cylinders & 4 in-line \\
Combustion chamber & Swirl chamber \\
Total displacement cm & $1.998 \mathrm{cc}(121.925 \mathrm{cu}$ in $)$ \\
Cylinder bore mm x piston stroke mm & $82.7 \times 93$ \\
Bore/stroke ratio & 0.89 \\
Compression ratio & $22.4: 1$ \\
Fuel system & Pump distributor-type injection \\
\hline
\end{tabular}

Before the experiment, the engine was run with diesel fuel for a period of 15 minutes to reach a steady state condition. Engine performance and exhaust emissions tests were conducted from a range of $20 \%$ to $60 \%$ load. The total mass concentration of the diesel PM on the composite filter was measured using a high precision electric balance. The filters were weighed under controlled temperature and relative humidity. 
Using dichloromethane, the SOF and DS can be extracted and the concentration can be measured.

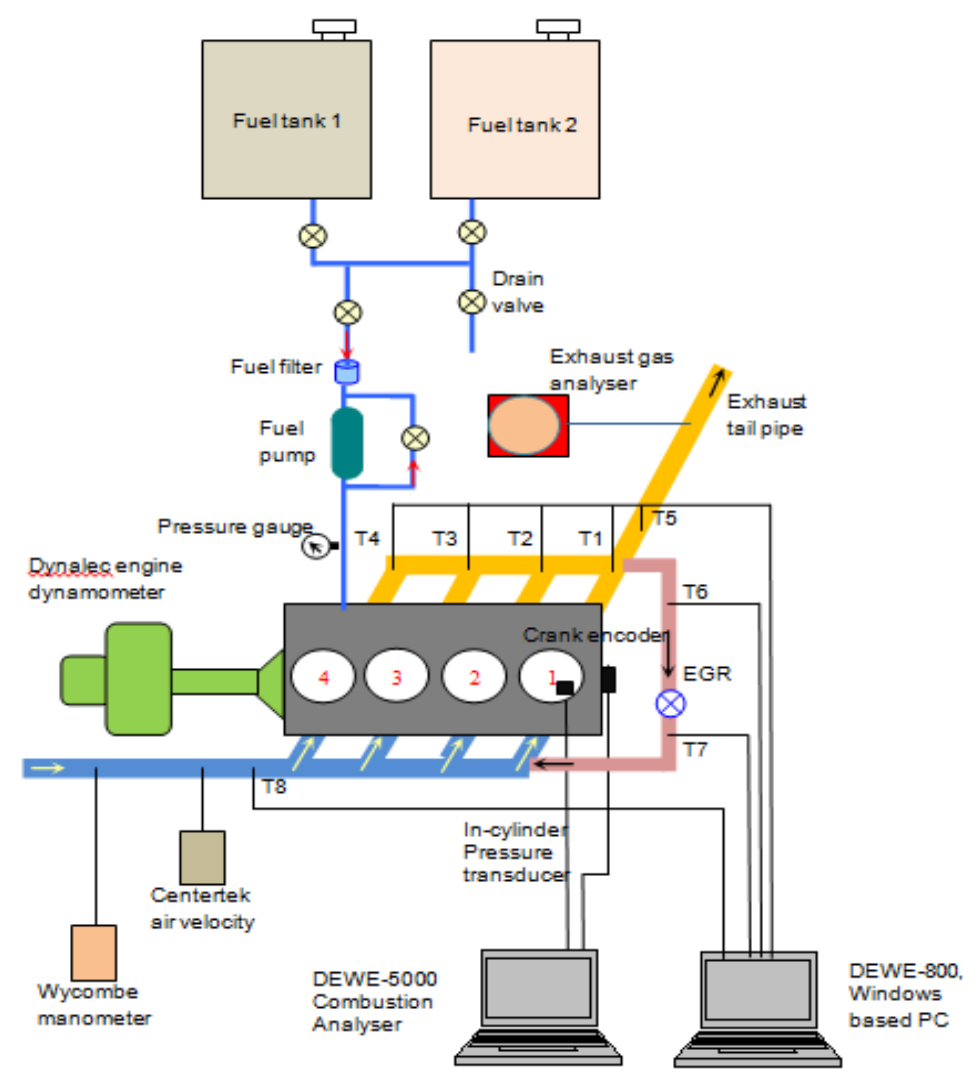

Figure 1. Schematic diagram of the engine test rig

Table 2. Properties of the fuels.

\begin{tabular}{lrrrrrr}
\hline Properties & Diesel & B20 & B20 E5 & B20 E10 & B20 E15 & B20 E20 \\
\hline Flash point $\left({ }^{\circ} \mathrm{C}\right)$ & 70 & 110 & 43 & 48 & 45 & 49 \\
Viscosity $\left(\mathrm{mm}^{2} / \varsigma\right.$ & 4.24 & 3.07 & 3.08 & 3.09 & 3.28 & 3.63 \\
Density $\left(\mathrm{kg} / \mathrm{m}^{3}\right)$ & 837 & 845 & 843 & 842 & 844 & 843 \\
Cetane number & 50 & 41.2 & 41.7 & 42.6 & 43.4 & 44.2 \\
\hline
\end{tabular}

Table 3. Specifications of filter paper

\begin{tabular}{ll}
\hline Name & Filter paper specifications \\
\hline Material & Composite filter (PTFE coated) \\
Trademark & Advantec \\
Type & PG-60 \\
Size & $47 \mathrm{~mm}^{2}$ \\
Quantity & 100 leaf \\
Lot Number & 20919702 \\
Manufacturer & Toyo Roshi Kaisya, Ltd. \\
\hline
\end{tabular}




\section{RESULTS AND DISCUSSION}

Figure 2 shows the variation of PM mass concentration with the load fueled with the diesel-methanol blended fuel. The engine was set at a constant speed of $2500 \mathrm{rpm}$. Due to the methanol's low energy content, the power will decrease using the diesel-methanol blended fuel. Figure 2 shows that, with the increase of methanol in blended fuels, the PM mass concentration for all loads is decreased at 10\% of methanol (PME20M10) and increases again with the increase of methanol content. The highest percentage reduction of PM concentration occurs at $60 \%$ load of PME20M10, which is $67.2 \%$ less than mineral diesel, while at $20 \%$ and $40 \%$ of PME20M10, the recorded reduction of PM is $55.1 \%$ and $35.0 \%$ respectively. Thus, the more methanol is added to the fuel until $10 \%$ of methanol, the greater the PM reduction achieved. However, when the methanol content is increased to more than $10 \%$, the PM concentration also starts to increase. The lower $\mathrm{PM}$ reduction can be explained, based on the graph in Figure 2. The overall results show that by using methanol in the PME20, the PM concentration is lower than the mineral diesel by up to $15 \%$ of methanol content. This is because the presence of fuel oxygen reduces the probability of rich zone formation and promotes the oxidation of PM in the fuel combustion. Thus, $10 \%$ of methanol content is the best mixture to get the greatest reduction of PM since methanol has a high oxygen content.

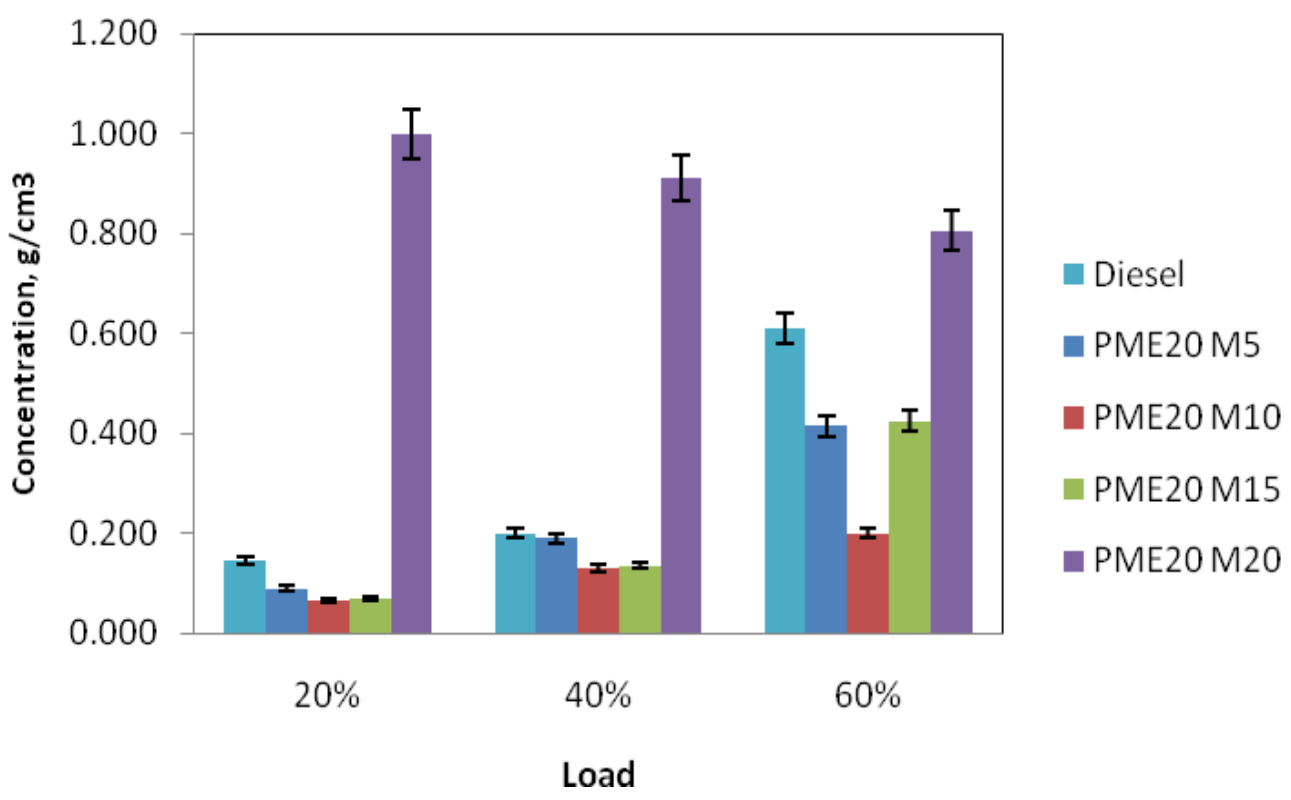

Figure 2. PM concentration

PM is mainly composed of two components: DS and SOF. There is one method to separate the PM into SOF and DS according to a previous study (Westerholm, Christensen, de Serves, \& Almen, 1999). Thus, in this study, PM emissions are affected by the methanol content and these components need to be separated in order to investigate the effects in the diesel engine. Figure 3 shows the DS components in the PM with the load fueled with diesel-ester-methanol fuels. The DS increased with the increase of the load. Figure 3 shows that the reduction of PM is more efficient at $10 \%$ of methanol content. For instance, at $10 \%$ methanol content, the DS concentration is tremendously reduced by $73.1 \%$ at $60 \%$ load, while at $20 \%$ and $40 \%$ load the DS reduces by $57.1 \%$ and $47.1 \%$ respectively. When the methanol content is increased to more than 
$10 \%$, the DS concentration is increased linearly. This is because the oxygen content present in the methanol helps to improve the surrounding oxygen conditions, which will benefit the combustion and prevent DS formation in the fuel oxidation reactor, although this is applicable only up to $10 \%$ of methanol contents. On the other hand, it can be seen that by increasing the methanol content up to $10 \%$, the DS component is slightly decreased.

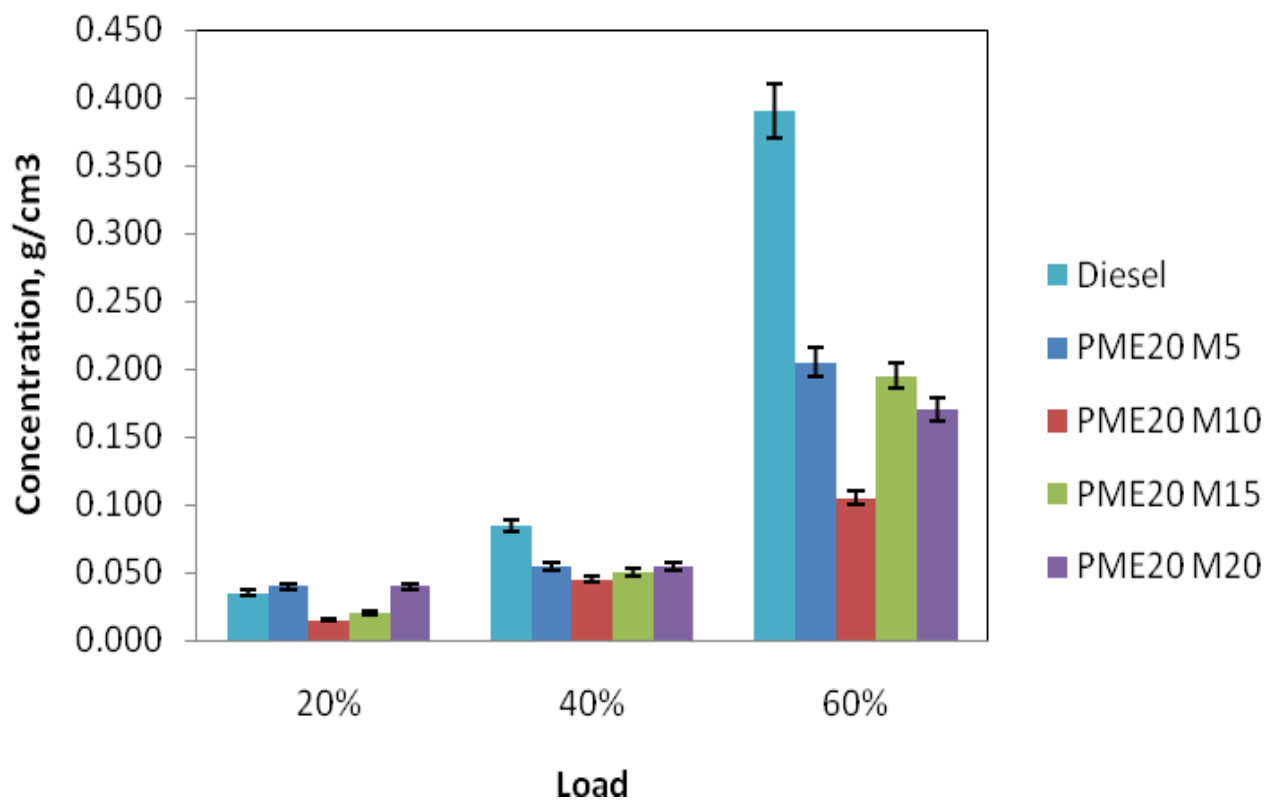

Figure 3. DS concentration

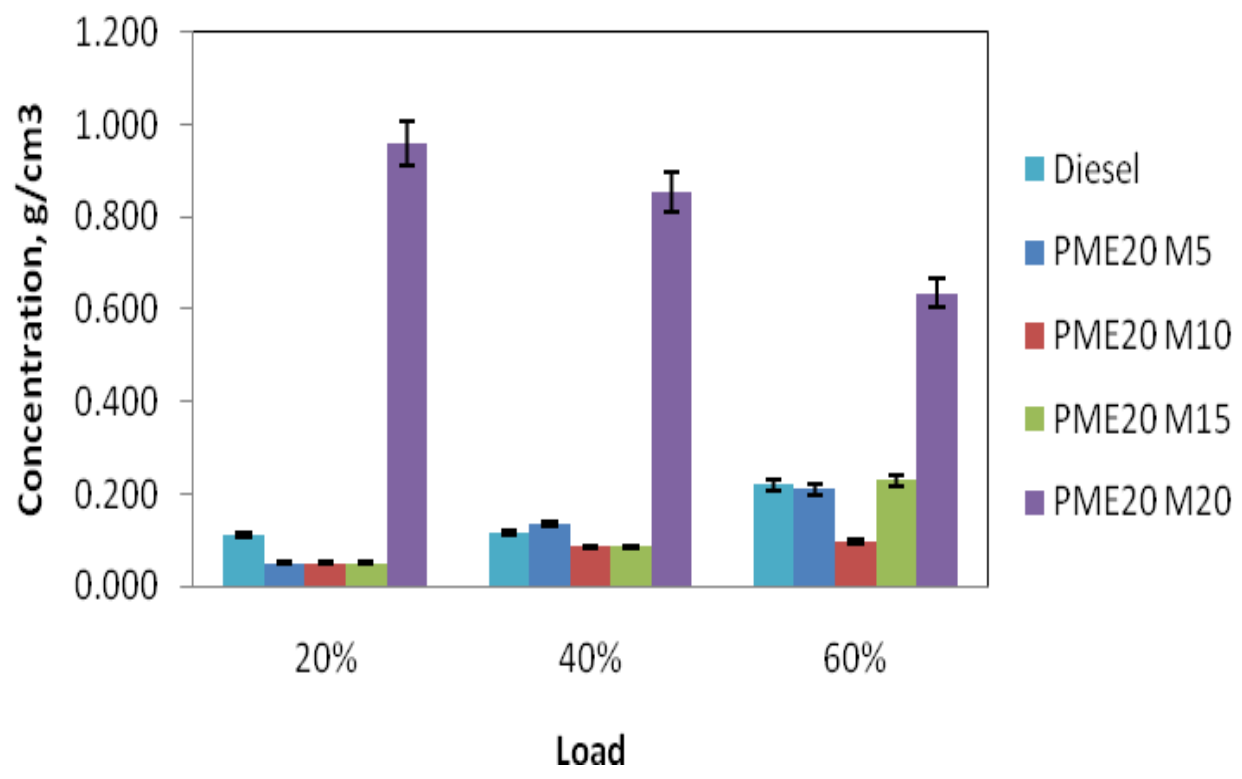

Figure 4. SOF concentration

The SOF in the PM is given in Figure 4. The SOF characteristics depend on the $\mathrm{HC}$ emission, where the SOF component is caused by the unburned $\mathrm{HC}$ absorbed by the DS. From the graph, with increasing load, SOF tends to increase linearly up to $15 \%$ of 
methanol content, while at $20 \%$ of methanol content, the SOF starts to decrease slightly until $60 \%$ of load. At higher loads, especially at $60 \%$ load, the SOF in the PM tends to increase as the methanol content increases. This is because the methanol provides a greater oxygen component in the fuel, and at higher load the fuel-air ratio is high and produces a high rate of oxidation. On the other hand, the evaporation latent heat of methanol is much higher than diesel, which decreases the temperature in the combustion chamber during the mixing formation. Therefore, it will not benefit SOF reduction. At higher load, the SOF becomes the main component in the PM and the SOF is composed of unburned $\mathrm{HC}$ which is easy to remove using an after-treatment method. Thus, by introducing an oxidation catalyst after-treatment, the PM can be reduced effectively.

\section{CONCLUSIONS}

The effects of methanol on the PM component for an IDI diesel engine fueled with PME20 were investigated. The analysis of this research can be summarized as follows:

1. Using the ester-methanol-diesel blends, the PM, SOF and DS can be reduced effectively at $10 \%$ of methanol content, but higher methanol content is not effective due to the high evaporation latent heat which brings down the combustion temperature.

2. As the load percentage is increased, the PM, SOF and DS also tend to increase except for the DS concentration when fueled with PME20 M20.

3. Understanding the process of PM emission formation in diesel engines is especially helpful to industries interested in developing engines in the future as a means to help control PM emissions.

\section{ACKNOWLEDGEMENTS}

Universiti Malaysia Pahang is greatly acknowledged for the technical and financial support provided under UMP Short Grant (RDU110112).

\section{REFERENCES}

Abdul-Khalek I.S., \& J.H., J. (1996). The influence of dilution conditions on diesel exhaust particle size distribution measurement. SAE Technical Paper 1999-011142.

Atadashi, I. M., Aroua, M. K., \& Aziz, A. A. (2010). High quality biodiesel and its diesel engine application: A review. Renewable and Sustainable Energy Reviews, 14(7), 1999-2008.

Azad, A. K., Ameer Uddin, S. M., \& Alam, M. M. (2012). A comprehensive study of di diesel engine performance with vegetable oil: An alternative boi-fuel source of energy. International Journal of Automotive and Mechanical Engineering, 5, 576-586.

Aziz Hairuddin, A., Wandel, A. P., \& Yusaf, T. (2013). Effect of different heat transfer models on a diesel homogeneous charge compression ignition engine. International Journal of Automotive and Mechanical Engineering, 8, 12921304. 
Bhaskar, K., Nagarajan, G., \& Sampath, S. (2010). Experimental investigation on cold start emissions using electrically heated catalyst in a spark ignition engine. International Journal of Automotive and Mechanical Engineering, 2, 105-118.

Brown, D. M., Wilson, M. R., MacNee, W., Stone, V., \& Donaldson, K. (2001). Sizedependent proinflammatory effects of ultrafine polystyrene particles: A role for surface area and oxidative stress in the enhanced activity of ultrafines. Toxicology and Applied Pharmacology, 175, 191-199.

Chen, H., Shi-Jin, S., \& Jian-Xin, W. (2007). Study on combustion characteristics and pm emission of diesel engines using ester-ethanol-diesel blended fuels. Proceedings of the Combustion Institute, 31(2), 2981-2989.

Gangwar, J. N., Gupta, T., \& Agarwal, A. K. (2012). Composition and comparative toxicity of particulate matter emitted from a diesel and biodiesel fuelled crdi engine. Atmospheric Environment, 46(0), 472-481.

Ghobadian, B., Najafi, G., \& Nayebi, M. (2013). A semi-empirical model to predict diesel engine combustion parameters. Journal of Mechanical Engineering and Sciences, 4, 373-382.

H, B. (2005). Physical characterization of particulate emissions from diesel engines: A review. Journal of Aerosol Science, 36(7), 896-932.

Huang, Z., Lu, H., Jiang, D., Zeng, K., Liu, B., Zhang, J., \& Wang, X. (2004). Engine performance and emissions of a compression ignition engine operating on the diesel-methanol blends. Proceedings of the Institution of Mechanical Engineers, Part D: Journal of Automobile Engineering, 218(4), 435-447.

Kitamura, T., Ito, T., Senda, J., \& Fujimoto, H. (2001). Detailed chemical kinetic modeling of diesel spray combustion with oxygenated fuels. SAE TRANSACTIONS, 110(3), 1560-1578.

Kulakoğlu, T. (2009). Effect of injection pressure on the performance and emissions of a diesel engine fueled with methanol-diesels blends. PhD Dissertation, Marmara University, İstanbul, Turkey.

Laurens, N., Koolwijk, P., \& De Maat, M. (2006). Fibrin structure and wound healing. Journal of Thrombosis and Haemostasis, 4(5), 932-939.

Lighty, J. S., Veranth, J. M., \& Sarofim, A. F. (2000). Factor governing their size and composition and implications to human health. Journal of the Air and Waste Management Association 50, 1565-1618.

Liotta, F. J., \& Montalvo, D. M. (1993). The effect of oxygenated fuels on emission from a modern heavy-duty diesel engine. SAE TRANSACTIONS, 102, 14201420.

Mamat, R., Yusop, A. F., Rahim, R., Aziz, A., \& Shah, L. A. (2013). Fuel physical characteristics of biodiesel blend fuels with alcohol as additives. Procedia Engineering, 53, 701-706.

Mat Yasin, M. H., Mamat, R., Sharma, K. V., \& Yusop, A. F. (2012). Influence of palm methyl ester (pme) as an alternative fuel in multicylinder diesel engine. Journal of Mechanical Engineering and Sciences, 3, 331-339.

Mat Yasin, M. H., Yusaf, T., Mamat, R., \& Fitri Yusop, A. Characterization of a diesel engine operating with a small proportion of methanol as a fuel additive in biodiesel blend. Applied Energy(0).

Miyamoto, N., Ogawa, H., Nurun, N. M., Obata, K., \& Arima, T. (1998). Smokeless, low nox, high thermal efficiency, and low noise diesel combustion with oxygenated agents as main fuel. SAE TRANSACTIONS, 107, 171-177. 
Mohanamurugan, S., \& Sendilvelan, S. (2011). Emission and combustion characteristics of different fuel in a hcci engine. International Journal of Automotive and Mechanical Engineering, 3, 279-292.

Oberdörster, G., Sharp, Z., Atudorei,V., Elder, A., Gelein, R., Kreyling,W., \& Cox, C. (2004). Translocation of inhaled ultrafine particles to the brain. Inhalation Toxicology, 16, 437-445.

Ozsezen, A. N., Canakci, M., \& Sayin, C. (2008). Effects of biodiesel from used frying palm oil on the performance, injection, and combustion characteristics of an indirect injection diesel engine. Energy \& Fuels, 22(2), 1297-1305.

Qi, D. H., Chen, H., Matthews, R. D., \& Bian, Y. Z. (2010). Combustion and emission characteristics of ethanol-biodiesel-water micro-emulsions used in a direct injection compression ignition engine. Fuel, 89(5), 958-964.

Rahim, R., Mamat, R., Taib, M. Y., \& Abdullah, A. A. (2012). Influence of fuel temperature on a diesel engine performance operating with biodiesel blended. Journal of Mechanical Engineering and Sciences, 2, 226-236.

Saeed, M., \& Henein, N. (1989). Combustion phenomena of alcohols in ci engines. Journal of Engineering for Gas Turbines and Power;(USA), 111(3).

Sayin, C., Uslu, K., \& Canakci, M. (2008). Influence of injection timing on the exhaust emissions of a dual-fuel ci engine. Renewable Energy, 33(6), 1314-1323.

Sundar Raj, C., \& Sendilvelan, S. (2010). Effect of oxygenated hydrocarbon additives on exhaust emission of a diesel engine. International Journal of Automotive and Mechanical Engineering, 2, 144-156.

Wang, L., Song, R., Zou, H., Liu, S., \& Zhou, L. (2008). Study on combustion characteristics of a methanol-diesel dual-fuel compression ignition engine. Proceedings of the Institution of Mechanical Engineers, Part D: Journal of Automobile Engineering, 222(4), 619-627.

Westerholm, R., Christensen, A., de Serves, C., \& Almen, J. (1999). Determination of polycyclic aromatic hydrocarbons(pah) in size-fractionated diesel particles from a light-duty vehicle. Society of Automotive Engineers, 400 Commonwealth Dr, Warrendale, PA, 15096, USA.

Yusaf, T., Hamawand, I., Baker, P., \& Najafi, G. (2013). The effect of methanol-diesel blended ratio on ci engine performance. International Journal of Automotive and Mechanical Engineering, 8, 1385-1395. 